\title{
Educação especial e a Covid-19: \\ o exercício da docência via atividades remotas
}

\section{Special education and Covid-19:}

the exercise of teaching via remote activities

\section{Educación especial y Covid-19:}

el ejercicio de la docencia a través de actividades a distancia

JOSIANE PEREIRA TORRES

Universidade Federal de Minas Gerais, Belo Horizonte-MG, Brasil.

\section{ADRIANA ARAÚJO PEREIRA BORGES}

Universidade Federal de Minas Gerais, Belo Horizonte-MG, Brasil.

\begin{abstract}
RESUMO: É apresentado um panorama da atuação de professores de educação especial frente as atividades remotas durante o período da pandemia da Covid-19. Professores que atuam na modalidade foram ouvidos através de um questionário autoaplicado. Os resultados apontam os desafios da adoção de atividades nesse formato, principalmente na utilização dos recursos tecnológicos. Enquanto o trabalho docente se intensificou, a participação dos estudantes diminuiu, evidenciando o impacto negativo desse momento na educação de alunos com deficiência.

Palavras-chave: Educação especial. Covid-19. Ensino remoto emergencial.
\end{abstract}

\begin{abstract}
An overview of the role of special education teachers in the face of remote activities during the Covid-19 pandemic period is presented. Teachers working in this area were heard through a
\end{abstract}

* Mestra e Doutora em Educação Especial pela Universidade Federal de São Carlos. Atualmente é professora da Universidade Federal de Minas Gerais e pesquisadora do Grupo de Estudos sobre Política Educacional e Trabalho Docente (GESTRADO). E-mail: <jtfisica@gmail.com>.

* Mestra em Psicologia pela Pontifícia Universidade Católica de Minas Gerais e Doutora em Educação pela Universidade Federal de Minas Gerais, mesma instituição na qual atualmente é professora. É vice-coordenadora do Grupo de Estudos sobre Política Educacional e Trabalho Docente (GESTRADO). E-mail: $<$ adriana.borges@terra.com.br>. 
self-applied questionnaire. The results point out to the challenges of adopting activities in this format, mainly in the use of technological resources. While teaching work intensified, student participation decreased, showing the negative impact of this moment on the education of students with disabilities.

Keywords: Special education. Covid-19. Emergency remote teaching.

RESUMEN: Se presenta una visión general del desempeño de los maestros de educación especial frente a las actividades remotas durante el período de la pandemia Covid-19. Se escuchó a los docentes que trabajan en la modalidad a través de un cuestionario autoadministrado. Los resultados apuntan a los desafíos de adoptar actividades en este formato, principalmente en el uso de recursos tecnológicos. Si bien el trabajo docente se intensificó, la participación de los estudiantes disminuyó, mostrando el impacto negativo de este momento em la educación de los estudiantes con necesidades educativas especiales.

Palabras clave: Educación especial. Covid-19. Educación remota emergencial.

\section{Introdução}



ano de 2020 ainda estava no início quando o mundo foi surpreendido pela notícia de que o Covid-19, vírus que havia se manifestado ainda no ano de 2019 na China, estava se espalhando por todos os países em uma velocidade avassaladora. Com o crescimento cada vez maior de infectados pelo vírus, as pessoas tiveram que se isolar e, como consequência, escolas do mundo todo foram fechadas. Toda essa situação acabou por evidenciar a desigualdade que já estava presente nos sistemas educacionais. No contexto brasileiro, em que essa realidade é mais grave tendo em vista as questões sociais e econômicas, professores da rede pública de ensino foram fortemente impactados. Diante da imprevisibilidade do retorno presencial das atividades escolares, diferentes redes de ensino se organizaram para ofertar o ensino remoto emergencial.

No Brasil a medida foi regulamentada pela Lei nº 14.040 (BRASIL, 2020a), que estabeleceu normas educacionais excepcionais a serem adotadas durante o estado de calamidade pública, com previsão da adoção da estratégia a critério dos sistemas de ensino durante o ano letivo afetado pela pandemia (BRASIL, 2020a). O Conselho Nacional de Educação (CNE) emitiu o parecer n⿳o 5 (BRASIL, 2020b) sobre a reorganização do calendário escolar e cômputo das atividades não presenciais para fins de cumprimento da carga horária mínima anual. No documento, é esclarecido que as atividades pedagógicas não 
presenciais se aplicam aos alunos de todas as etapas, níveis ou modalidades, inclusive aos alunos do Público-Alvo da Educação Especial (PAEE) ${ }^{1}$. O documento reafirma ainda a necessidade da garantia da qualidade dos serviços educacionais por parte dos sistemas de ensino, a partir da acessibilidade e da oferta do atendimento educacional especializado (AEE). Nesse contexto, os professores que atuam nas salas de recursos multifuncionais seriam responsáveis por trabalhar junto com os professores regentes, articular ações com a equipe escolar, adequar materiais e prover orientação às famílias, além de elaborar planos de ensino individualizados (PEI) (BRASIL, 2020b). Além disso,

\footnotetext{
algumas situações requerem ações mais específicas por parte da instituição escolar, como nos casos de acessibilidade sociolinguística aos estudantes surdos usuários da Língua Brasileira de Sinais (Libras), acessibilidade à comunicação e informação para os estudantes com deficiência visual e surdocegueira, no uso de códigos e linguagens específicas, entre outros recursos que atendam àqueles que apresentem comprometimentos nas áreas de comunicação e interação (BRASIL, 2020b, p.15).
}

O documento não sinaliza com clareza as ações mais específicas que poderiam ser desenvolvidas com os alunos que apresentam dificuldades comunicacionais no contexto do ensino remoto emergencial. Posteriormente, o CNE emite o Parecer n⿳o 11 (BRASIL, 2020c) que trata da retomada do ensino presencial nas escolas. Embora o Parecer afirme que os alunos do PAEE devem seguir as mesmas orientações gerais de retorno às atividades presenciais que os outros alunos, uma série de outras orientações são listadas para o retorno desse público às atividades presenciais, quando forem liberadas. Dentre elas, a orientação de que alguns alunos devem ser privados das interações presenciais: os surdos, por não usarem as máscaras, já que necessitam visualizar a boca do interlocutor; estudantes que necessitam de contato físico direto com um profissional de apoio escolar; estudantes cegos, que necessitam tocar em objetos e pessoas para se locomover; alunos com deficiência intelectual, que teriam dificuldades em entender orientações de cuidado; estudantes com autismo que teriam dificuldades em seguir regras; além de estudantes com deficiência física que seriam mais suscetíveis à contaminação (BRASIL, 2020c).

Os pareceres evidenciam a grande dificuldade dos sistemas educacionais em conseguir articular de maneira satisfatória o ensino remoto para um público que engloba alunos com características específicas. O Parecer $n^{0} 5$ (BRASIL, 2020b) reafirma o direito à educação do PAEE no contexto da pandemia, mas não contempla orientações que possam auxiliar os sistemas de ensino na tomada de decisões. Já o parecer n⿳ํㅡㄴ 11 (BRASIL, 2020c) emite um juízo de valor sobre a volta dos alunos PAEE às aulas presenciais, desconhecendo, primeiro, a enorme variabilidade de casos numa mesma condição. Não é possível considerar que todos os alunos com autismo tenham dificuldades em seguir regras sociais ou que todos os alunos que necessitem de um profissional de apoio estejam em risco se os protocolos de higiene forem seguidos. Em segundo lugar, o Parecer cria uma situação em que os sistemas de ensino podem alegar que não estão aptos a receber 
os alunos do PAEE, mantendo-os por tempo indeterminado longe da escola, recebendo um ensino que parece não atender as possíveis particularidades desse público.

Os desafios dos professores de Educação Especial no contexto da pandemia podem ser melhor compreendidos a partir da análise dos dados referentes a uma pesquisa nacional, realizada entre os dias 08 a 30 de junho de 2020, com professores de todo Brasil. O presente estudo faz parte dessa pesquisa mais ampla denominada Trabalho docente em tempos de Pandemia, desenvolvida pelo Grupo de Estudos sobre Política Educacional e Trabalho Docente da Universidade Federal de Minas Gerais (Gestrado/UFMG) em parceria com a Confederação Nacional dos Trabalhadores em Educação (CNTE) (Gestrado-CNTE, 2020).

Neste artigo são apresentados os resultados referentes à amostra de professores que atuavam na modalidade da Educação Especial e apresentaram anuência por meio do Termo de Consentimento Livre e Esclarecido. Nessas condições, o estudo foi composto por 1.133 professores(as) de Educação Especial da Educação Básica. Os participantes foram recrutados por meio de adesão espontânea, logo a amostra é não-probabilística.

A coleta de dados ocorreu por meio de um questionário on-line autoaplicado disponibilizado na plataforma Google Forms. O questionário foi composto por cinco blocos de questões objetivas e compreendeu cinco categorias.

A tabulação bem como o processo de análises dos dados ocorreu por meio dos softwares Microsoft Excel e o pacote IBM SPSS Statistics Base (Versão 21.0). Os resultados e discussões encontram-se organizados em seções, definidas com base nas categorias do questionário.

\section{Resultados e discussões}

A Tabela 1 apresenta as informações básicas que caracterizam os participantes do estudo. Do lado esquerdo da tabela são apresentados os dados percentuais de caracterização geral (sexo e faixa etária) bem como os dados de caracterização profissional (rede e etapa de atuação na educação básica). No lado direito são apresentados os dados percentuais de distribuição dos participantes entre os estados brasileiros.

\section{Tabela 1: Dados de caracterização dos participantes}

\begin{tabular}{l|l|l|l}
\hline Varíavel & $\mathbf{\%}$ & Estado & $\mathbf{\%}$ \\
\hline Sexo & & AC & $3,5 \%$ \\
\hline Feminino & $86,1 \%$ & AL & $1,1 \%$ \\
\hline Masculino & $13,8 \%$ & AP & $0,4 \%$ \\
\hline Faixa etária & & AM & $0,5 \%$
\end{tabular}




\begin{tabular}{|l|l|l|l|}
\hline $19-28$ & $5,47 \%$ & BA & $2,0 \%$ \\
\hline $29-38$ & $23,65 \%$ & CE & $11,8 \%$ \\
\hline $39-48$ & $40,07 \%$ & DF & $4,9 \%$ \\
\hline $49-58$ & $25,33 \%$ & ES & $5,2 \%$ \\
\hline $59-68$ & $5,38 \%$ & GO & $3,3 \%$ \\
\hline $69-78$ & $0,09 \%$ & MA & $0,1 \%$ \\
\hline Rede de atuação & & MT & $1,3 \%$ \\
\hline Pública Estadual & $41,92 \%$ & MS & $18,6 \%$ \\
\hline Pública Federal & $0,88 \%$ & MG & $8,4 \%$ \\
\hline Pública Municipal & $57,19 \%$ & PA & $0,4 \%$ \\
\hline Atua em mais de uma rede & $12,89 \%$ & PB & $4,6 \%$ \\
\hline Etapa & & PR & $14,0 \%$ \\
\hline Educação Infantil & $7,50 \%$ & PE & $2,1 \%$ \\
\hline Ensino Fundamental - Anos Iniciais & $33,27 \%$ & PI & $0,5 \%$ \\
\hline Ensino Fundamental - Anos Finais & $14,39 \%$ & RJ & $2,0 \%$ \\
\hline Ensino Médio & $5,47 \%$ & RN & $1,1 \%$ \\
\hline Atua em mais de uma etapa & $39,30 \%$ & RS & $2,8 \%$ \\
\hline & & RO & $2,8 \%$ \\
\hline & & RR & $0,8 \%$ \\
\hline & & SC & $3,6 \%$ \\
\hline & & TO & $3,8 \%$ \\
\hline & & $0,2 \%$ \\
\hline & & $0,1 \%$ \\
\hline
\end{tabular}

Fonte: Com base nos dados da pesquisa Gestrado, 2020.

Todos os estados brasileiros foram representados na pesquisa, sendo que em alguns estados (MS, PR e CE) houve uma maior quantidade de participantes, enquanto em outros a representação foi consideravelmente menor (TO, $\mathrm{MA} \mathrm{e} \mathrm{SE,} \mathrm{por} \mathrm{exemplo).}$

A amostra da pesquisa foi majoritariamente feminina, correspondendo a $86,1 \%$ ( $n=976)$, enquanto os professores do sexo masculino correspondem a 13,8\% (n=157). A idade média das participantes do sexo feminino foi de 44,2 anos com variação de 19-70. Já do sexo masculino a idade média foi de 41,2 e variação de 22-64. De certa forma, essa é uma distribuição esperada, visto que, segundo os dados oficiais de número de docentes da Educação Especial no Brasil no ano de 2019, por exemplo, dos professores atuantes na 
modalidade, 73,6\% correspondia a professoras do sexo feminino (INEP, 2020). Somado aos desafios da adoção do ensino remoto, é importante ainda refletir sobre os desafios relacionados à questão de gênero e à sobrecarga de trabalho, considerando que a amostra foi composta na maioria por mulheres que compartilham e conciliam as demandas da atuação docente com as atividades domésticas.

Em relação à redes de atuação, o número mais expressivo de respondentes foi o de professores atuantes na rede municipal, correspondendo a 57,2\%, na sequência a rede estadual, com $41,9 \%$. e apenas $0,9 \%$ dos professores representam a rede federal. Dentre os professores participantes, $12,9 \%$ relataram atuar em mais de uma rede, concomitantemente.

Quanto à(s) etapa(s) de atuação, 60,6\% dos professores relataram atuar em apenas uma etapa da educação básica, sendo: 7,5\% na educação infantil; 33,3\% no ensino fundamental - anos iniciais; $14,4 \%$ no ensino fundamental - anos finais e 5,5\% no ensino médio. E 39,3\% dos professores relataram atuar em mais de uma etapa da educação básica.

Considerando o número de matrículas de alunos do PAEE no ensino comum, nota-se que maior quantitativo se encontra nas primeiras etapas de ensino. Os dados indicam uma diminuição gradativa nos níveis mais altos, como nos anos finais do ensino fundamental e ensino médio (INEP, 2020). Esse fato justificaria menor demanda de professores na modalidade, o que é perceptível na amostra deste estudo, bem como nos dados oficiais de registro de docentes no âmbito nacional.

\section{Atividades remotas mediadas por tecnologias}

Todos os professores relataram desenvolver atividades de ensino remoto no momento da pesquisa, sendo que $96,6 \%$ disseram que estavam realizando atividades em casa, enquanto apenas $3,4 \%$ estavam realizando as atividades na escola. No entanto, a adoção repentina dessa estratégia pode ter sido acompanhada por apreensão, pois $85,7 \%$ dos professores responderam que não tinham experiência anterior em ministrar aulas nesse formato e somente 14,3\% indicaram possuir tal experiência. Pouca experiência com as aulas remotas era esperada, já que a regulamentação da Educação Básica no País prevê que esse nível de ensino ocorra de forma presencial, resguardando os casos específicos previstos no Decreto nº 9.057 (BRASIL, 2017b). Em relação aos alunos com deficiência, suas especificidades podem, em alguns casos, requerer estratégias adequadas e que necessitam ser construídas no caso-a-caso.

Com relação às respostas dos professores de Educação Especial no que diz respeito às percepções sobre o uso das tecnologias digitais, quase a metade considera regular lidar com as tecnologias digitais, 30,4\% consideram fácil/muito fácil e 20,5\% consideram difícil/muito difícil. A percepção dos professores em relação à utilização das tecnologias pode estar relacionada à formação recebida. A formação para o uso das tecnologias de 
informação e comunicação (TIC), como ferramentas para o ensino, pode não ser suficiente para garantir que os professores a utilizem, pois o que impulsiona seu uso é o quão bem capacitado esse profissional se sente após receber a formação (OCDE, 2020).

Em consonância com o Plano Nacional de Educação, o decreto n⿳0 9.204 de 23 de novembro de 2017 instituiu o Programa de Inovação Educação Conectada, cujo objetivoé "apoiar a universalização do acesso à internet em alta velocidade e fomentar o uso pedagógico de tecnologias digitais na educação básica” (BRASIL, 2017a). Um dos princípios do programa é o "incentivo à formação de professores e gestores em práticas pedagógicas com tecnologia e para uso de tecnologia" (BRASIL, 2017a, art. 3) e dentre as ações prevê "oferta de cursos de formação de professores para o uso da tecnologia em sala de aula" (BRASIL, 2017a, art. 4) cuja oferta compete ao Ministério da Educação (art. $10 \S 3^{\circ}$ ). No entanto, apenas 41\% dos professores do Ensino Fundamental, no Brasil, utilizam tecnologias em suas aulas, e mais de 30\% dos professores do Ensino Médio pontuaram não participar de atividades formativas relacionadas ao uso das TIC, além de relatarem necessidade de formação nessa área (OCDE, 2020).

Laprairie e Hinson (2006) apontam a necessidade de promover planos que garantam que as escolas realizem uma boa transição entre o ensino presencial para um ensino mediado por tecnologias, diante de desastres. Nesse contexto, seriam previstas, por exemplo, infraestrutura tecnológica e capacitação dos professores; no entanto, tomando como exemplo os resultados do último Pisa, a maioria dos sistemas educacionais dos países participantes não dispõe de recursos suficientes para garantir que os estudantes aprendam de forma online. No Brasil, em específico, a estimativa é de um computador disponível na escola para cada quatro estudantes (REIMERS; SCHLEICHER, 2020). No caso dos alunos com deficiência, é importante destacar que em muitos casos apenas fornecer recursos tecnológicos pode não ser suficiente, tais recursos precisam ser acessíveis. Teclados adaptados, softwares de fala, lupas de tela, anotadores em braile são apenas alguns exemplos de tecnologia assistiva que, na maior parte das vezes, não estão disponíveis devido à falta de recursos financeiros ou devido à falta de formação dos professores para auxiliar os alunos na utilização (UNESCO, 2020).

O gráfico 1 exibe as respostas dos professores quanto a ter participado ou encontrar-se participando de alguma formação para uso de tecnologias digitais em sala de aula.

\section{Gráfico 1: Formação para tecnologias digitais}




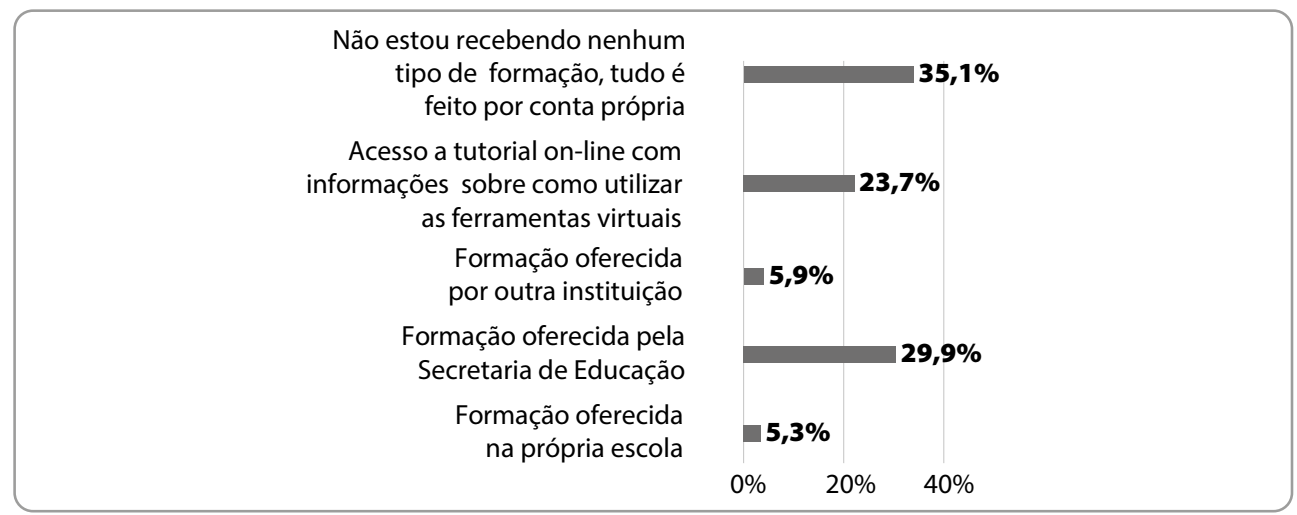

Fonte: Com base nos dados da pesquisa Gestrado, 2020.

Destaca-se que 35,1\% dos professores de Educação Especial indicaram não estar recebendo nenhuma formação para atuar nesse formato. Conforme aponta Arruda (2020), a situação emergencial imposta pela Pandemia da Covid-19 forçou a escola a reconfigurar-se, o que consequentemente, não permitiu planejamentos robustos a curto ou médio prazo. É importante entender que a formação para o uso das TIC pelos professores da Educação Especial é ainda mais complexa:

A ausência de profissionais capazes de utilizar os recursos da tecnologia assistiva enviados pelo Estado para as salas de recursos multifuncionais pode prejudicar ou mesmo impedir o desenvolvimento dos alunos que dependem, muitas vezes, dessas ferramentas tecnológicas para terem acesso ao currículo e participarem das atividades propostas em sala de aula (GIROTO et al., 2012, p.18).

Se no ensino presencial já havia uma lacuna nessa formação, o ensino remoto evidenciou ainda mais a necessidade de investimento na formação dos professores de Educação Especial para a utilização dos recursos tecnológicos para o acompanhamento dos alunos do PAEE.

\section{Condições para atividades não presenciais}

Em relatório publicado recentemente (REIMERS; SCHLEICHER, 2020), a OCDE reforça que mais que o ambiente físico ou a infraestrutura da escola, os professores desempenham um papel essencial na experiência de aprendizagem dos alunos, e que no cenário atual em que a aprendizagem online se materializa como alternativa dominante, a atuação desses profissionais pode ter importância maior ainda. No entanto, há de se considerar a relevância de oferecer condições adequadas para esses profissionais desempenharem essas atividades. 
Os dados da pesquisa demonstram que, considerando a disposição de recursos necessários para ministrar aulas remotas, $84,6 \%$ dos professores responderam possuir em suas casas tais recursos, enquanto $15,4 \%$ disseram não possuir. No entanto, a maioria dos professores que possuem o recurso não detém seu uso exclusivo, ou seja, 55,7\% deles reportaram dividir com outras pessoas da casa.

Dentre os recursos disponíveis para aulas remotas, $66,1 \%$ dos professores da Educação Especial indicaram o notebook como principal recurso, seguido do aparelho celular com $24,4 \%$ das respostas, tablet com 7,1\% e 2,4\% dos professores indicaram o uso de computador com desktop. Em relação ao acesso à internet, 55,2\% $(n=625)$ dos professores da Educação Especial indicaram o uso exclusivo da internet banda larga para desenvolvimento das atividades remotas; $10,8 \%$ outro tipo (rádio, discada etc.); 9,4\% de acesso por meio do plano de dados do celular; e 0,1\% indicaram não possuir acesso à internet em sua residência. Dentre esses, $24,5 \%$ indicaram possuir acesso a mais de uma opção de internet, sendo que a combinação que mais se destacou foi a banda larga associada com plano de dados do celular (21,2\%).

No Brasil, segundo os últimos dados divulgados pela Pesquisa Nacional por Amostra de Domicílios Contínua, sobressai o uso do aparelho celular nos domicílios como recurso prioritário para acesso à internet, com o computador em segunda colocação, sendo o tablet o aparelho menos comum segundo a pesquisa (IBGE, 2020). Com relação ao acesso à internet, no ano de 2018, em 79,1\% das residências brasileiras havia a utilização da internet, sendo que $80,2 \%$ é do uso por meio dos dados móveis e 75,9\% banda larga (IBGE, 2020).

Considerando o cenário educacional, a ampliação da conectividade e acesso à internet podem ser fatores imperativos no sentido de garantir um maior aproveitamento das oportunidades de aprendizado que as tecnologias são capazes de proporcionar. Mas esse pode ser um obstáculo considerável, pois o acesso mostra-se ainda incipiente em alguns países (OCDE, 2020), em específico nos da América Latina, em maior desvantagem no que diz respeito à garantia de conectividade em comparação com os demais países da OCDE (REIMERS; SCHLEICHER, 2020).

\section{Condições de trabalho docente}

Segundo os professores da Educação Especial participantes dessa amostra, 83,6\% consideram que a dedicação das horas de trabalho para preparação das aulas remotas aumentou em comparação à preparação das aulas presenciais, enquanto 12,1\% consideram que essa dedicação permaneceu a mesma e apenas $4,3 \%$ dos professores consideram que houve uma diminuição. Esse resultado indica que a adoção desse formato de aulas pode exigir mais dedicação por parte dos professores de educação especial.

A literatura discute os benefícios que estudantes do PAEE podem obter quando há a atuação em colaboração do professor de Educação Especial e do professor do ensino 
comum (MENDES; VILARONGA; ZERBATO, 2014). No entanto, o momento atual pode ser um fator complicador para que ocorra a atuação desses profissionais na perspectiva da colaboração. Além disso, o aumento das demandas do professor de Educação Especial pode estar associado ao fato de que os conteúdos curriculares do ensino comum no formato remoto, podem não estar atendendo todas as demandas dos estudantes do PAEE. É preciso lembrar que a promoção da acessibilidade curricular é uma das funções do professor de Educação Especial, cuja atividade pode apresentar-se mais desafiadora no contexto digital para alunos com deficiência.

O gráfico 2 exibe o percentual de respostas dos professores quanto ao tipo de atividade que eles realizavam no momento de aplicação do questionário.

\section{Gráfico 2: Porcentagem de respondentes que citaram/assinalaram cada atividade desenvolvida}

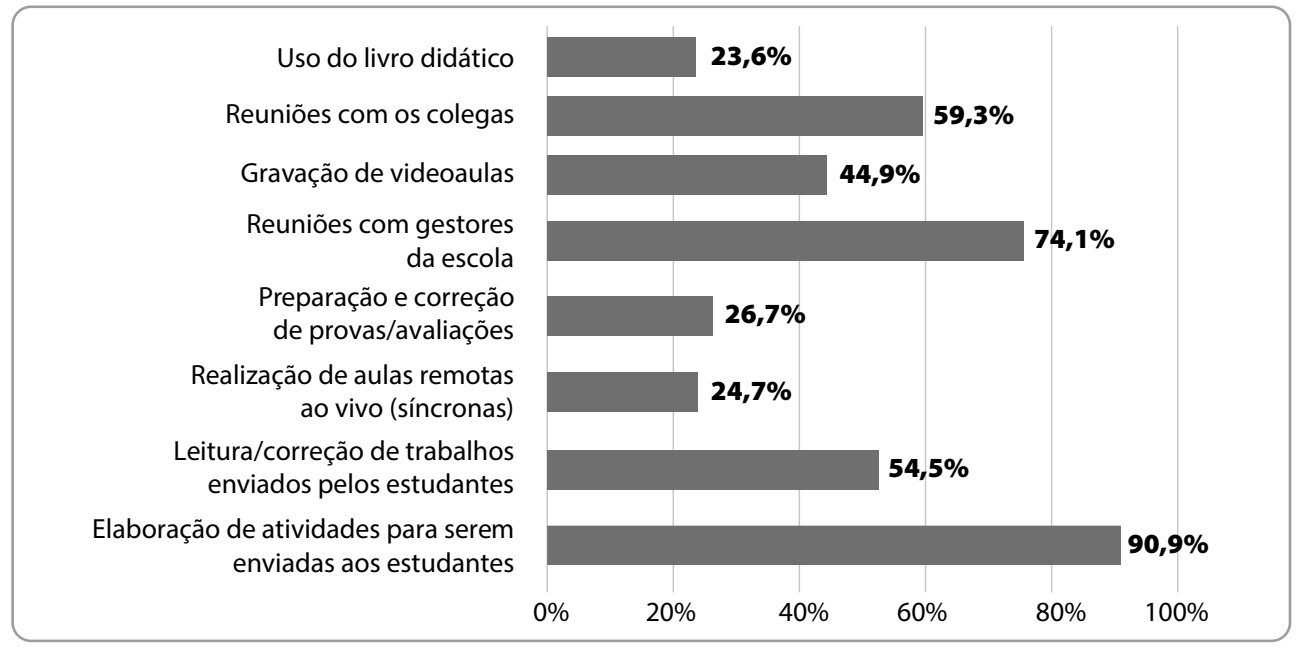

Fonte: Com base nos dados da pesquisa Gestrado, 2020.

Considerando, a possibilidade de múltiplas respostas para essa questão, 90,9\% dos 1.133 professores assinalaram que estavam realizando a atividade de Elaboração de atividades para serem enviadas aos estudantes, sendo essa a atividade assinalada com maior frequência pelos professores. Já o uso do livro didático ficou como a atividade assinalada com menor frequência, considerando que $23,6 \%$ dos professores indicaram essa atividade.

Em relação aos suportes que a rede/escola ofertava aos professores para a realização das atividades remotas, considerando a possibilidade de múltiplas respostas, nota-se pelos dados apresentados no gráfico 3 que a ausência total de suporte apresenta baixo percentual (11,2\%) comparada às possibilidades de suporte que os professores estavam recebendo. Na maioria, os professores indicaram que as redes e/ou escolas têm ofertado suporte para o desenvolvimento das atividades remotas. 


\section{Gráfico 3: Suportes recebidos pela rede/escola para a realização das} atividades remotas

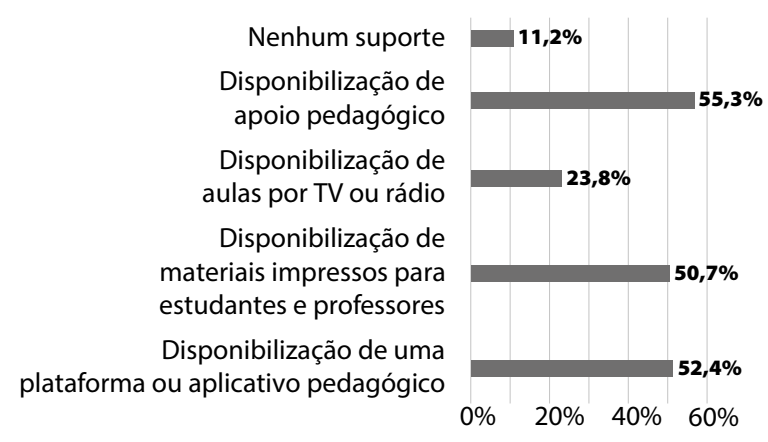

Fonte: Com base nos dados da pesquisa Gestrado, 2020.

\section{Relação com os estudantes nas atividades remotas}

Estudos indicam que a adoção de aulas remotas pode afetar consideravelmente populações que, tradicionalmente, enfrentam a desvantagem, como os estudantes do PAEE. No contexto internacional, pesquisadores (MOHAN, 2020; LUCAS; NELSON; SIMS, 2020; SAMAILA et al., 2020) apontam que os estudantes com deficiências sofreram impactos negativos com o fechamento das escolas e adoção de aulas remotas. A adoção de atividades nesse formato, as quais são mediadas por TIC pode não apresentar a acessibilidade necessária para algumas especificidades particulares (IANNIZZOTTO et al., 2020) e, dessa forma, promover e/ou reforçar práticas de exclusão. Por exemplo, a tecnologia pode não garantir a acessibilidade a estudantes cegos ou surdos, a independência necessária para executar atividades nesse formato pode não ser possível para uma parcela de estudantes e, ainda, a ausência da rotina diária na escola pode comprometer o envolvimento de estudantes sensíveis a mudanças, como alguns estudantes com autismo (UNESCO, 2020), além de inúmeros serviços que somente o contato físico pode oferecer.

Nesse sentido, nessa seção apresentamos os resultados referentes à percepção dos professores participantes quanto ao envolvimento de seus alunos durante a realização dessas atividades. Os resultados nos fornecem um panorama de alguns dos desafios que os estudantes PAEE têm vivenciado durante esse período na perspectiva de seus professores de educação especial.

Na política vigente (BRASIL, 2008), o modelo de serviço regulamentado é o AEE, o qual prevê atividades de complementação e suplementação para suporte ao ensino comum (BRASIL, 2011). Em relação à organização das atividades com os estudantes durante as atividades remotas, os professores indicaram com maior prevalência a opção "Estou adaptando o conteúdo estipulado em atividades que eles consigam realizar com autonomia 
ou mínimo apoio", seguida pela opção "Estou mantendo o planejamento e conteúdos estipulados antes do início da quarentena" e com menor proporção $(0,9 \%)$ foi indicada a opção "Estou priorizando os conteúdos curriculares cobrados pelos sistemas de avaliação (nacionais e locais)".

Quanto à percepção dos professores sobre a participação dos estudantes nas atividades propostas, apenas 4,59\% consideraram um aumento na participação, enquanto $14,74 \%$ mencionaram que essa participação se manteve igual. O resultado que chama a atenção é que a maior parte dos professores participantes consideram que essa participação diminuiu (49,16\% considera que diminuiu muito e $31,51 \%$ considera que diminuiu drasticamente).

Aos professores que responderam (n=914) que houve diminuição da participação no período de atividades remotas foi solicitado que indicassem o(s) fator(es) que consideram ter influenciado a diminuição. Os resultados encontram-se apresentados no gráfico 4.

\section{Gráfico 4: Fatores que podem ter influenciado a diminuição do interesse dos estudantes, segundo os professores}

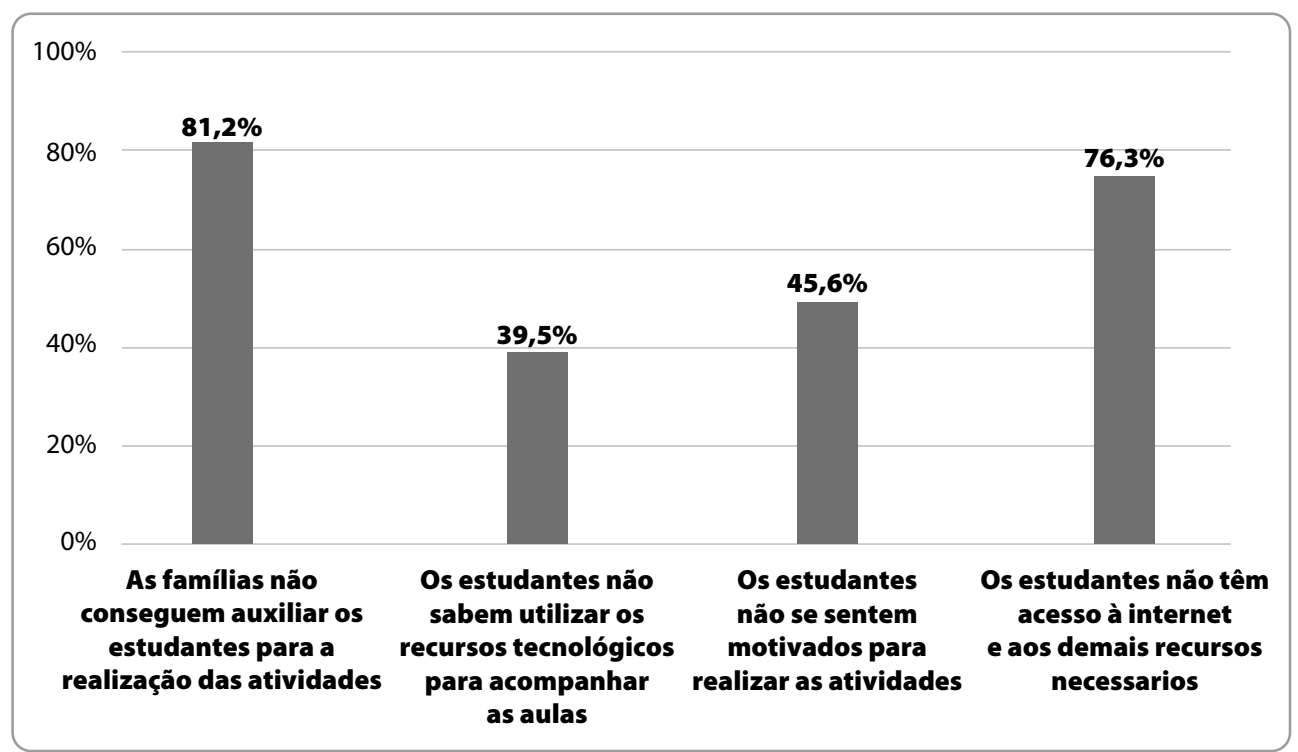

Fonte: Com base nos dados da pesquisa Gestrado, 2020.

Considerando que cada professor poderia indicar mais de um item, segundo eles os fatores que mais tem comprometido a participação dos estudantes durante o período está relacionado à dificuldade das famílias em oferecer apoio aos estudantes (81,2\%) e à falta de acesso à internet e demais recursos (76,3\%). Nessa perspectiva, é importante frisar que estudantes do PAEE podem enfrentar mais barreiras no ensino à distância $e$ provavelmente terão mais dificuldades para retornar às escolas quando isso for possível, correndo maior risco de desistir da escola (UNITED NATIONS, 2020). 
Muitos argumentos materializaram-se nos discursos em busca de justificar a importância da manutenção das aulas, de que seria importante para evitar perdas cognitivas dos alunos; ou ainda para manter os alunos em atividade durante o período; para justificar a continuidade do recebimento dos salários dos professores, dentre outros. Nessa perspectiva, na Tabela 2 encontram-se os percentuais de respostas dos professores distribuídos numa escala likert de concordância/discordância com afirmações que versavam sobre as percepções sobre a função das atividades remotas para os alunos PAEE.

\section{Tabela 2: Percepções dos professores quanto a função das aulas remotas}

\begin{tabular}{|c|c|c|c|c|c|}
\hline Afirmações & $\begin{array}{l}\text { Discordo } \\
\text { totalmente }\end{array}$ & $\begin{array}{l}\text { Discordo } \\
\text { parcialmente }\end{array}$ & $\begin{array}{l}\text { Não } \\
\text { concordo, } \\
\text { nem } \\
\text { discordo }\end{array}$ & $\begin{array}{l}\text { Concordo } \\
\text { parcialmente }\end{array}$ & $\begin{array}{l}\text { Concordo } \\
\text { totalmente }\end{array}$ \\
\hline $\begin{array}{l}\text { a) Permite que } \\
\text { os estudantes } \\
\text { tenham } \\
\text { atividades para } \\
\text { fazer em casa }\end{array}$ & $7,1 \%$ & $12,6 \%$ & $7,8 \%$ & $37,1 \%$ & $35,5 \%$ \\
\hline $\begin{array}{l}\text { b) Possibilita a } \\
\text { continuidade } \\
\text { aos contéudos } \\
\text { que precisam ser } \\
\text { trabalhados }\end{array}$ & $10,9 \%$ & $21,4 \%$ & $11,7 \%$ & $38,5 \%$ & $17,5 \%$ \\
\hline $\begin{array}{l}\text { c) Possibilita } \\
\text { contato com os } \\
\text { estudantes e as } \\
\text { famílias }\end{array}$ & $12,0 \%$ & $15,2 \%$ & $9,4 \%$ & $38,0 \%$ & $27,3 \%$ \\
\hline
\end{tabular}
d) Garante que não será necessária a reposição de
$6,4 \%$
$19,9 \%$
$13,9 \%$
$27,6 \%$
$17,8 \%$
aulas depois
e) Justifica o recebimento do
$9,3 \%$
$10,5 \%$
$11,4 \%$
$17,7 \%$
$48,4 \%$ salário normal
f) Os estudantes
não tem
acesso aos recursos para acompanhar as $6,4 \%$ $16,9 \%$
$10,6 \%$
$41,3 \%$ $24,7 \%$ as atividades 
g) Os estudantes

não têm

autonomia para

acompanhar

$9,3 \%$

$22,8 \%$

$11,9 \%$

$37,2 \%$

$18,8 \%$

os contéudos e

atividades

h) As famílias

não conseguem

realizar a

mediação

necessária

para garantir

$7,2 \%$

$15,5 \%$

$8,3 \%$

$40,2 \%$

$28,7 \%$

a execução

das atividades

propostas e a

aprendizagem

Fonte: Com base nos dados da pesquisa Gestrado, 2020.

Esses resultados demonstram que, na perspectiva dos professores, há maior concordância nas afirmações que remetem à ocupação dos alunos durante esse período (item a) e possibilidade de manter contato com eles e suas famílias (item c), enquanto a função de desenvolver o currículo escolar não é de muita concordância entre os professores (itens b; d). A dificuldade de acesso e motivação por parte dos estudantes são fatores de considerável concordância entre os professores como causa de comprometimento para acompanhar as atividades remotas (itens f; g). E a distribuição de percentuais para a afirmação do item $\mathrm{h}$ reforça que há compreensão do papel da família como mediadora na execução das atividades, fato já observado de forma expressiva no gráfico 4 .

Em relação às percepções dos professores quanto ao aproveitamento dos conteúdos que foram desenvolvidos durante as atividades remotas após o período de isolamento social, uma parcela pequena dos professores compreende que o conteúdo terá sido trabalhado com sucesso $(5,6 \%)$, enquanto a maior parte dos professores $(n=1069)$ indicou que esse conteúdo deverá ser retomado parcialmente $(72,5 \%)$ ou até mesmo de forma integral (21,9\%). Nesse contexto, questionamos qual a função que o ensino remoto tem desempenhando nesse período para o PAEE. Considerando os resultados e o contexto desta pesquisa, os professores indicam com suas respostas que, academicamente, essas atividades podem ser apenas uma falácia.

\section{Considerações finais}

A Pandemia da Covid-19 desencadeou uma crise global sem precedentes, afetando vários setores, dentre eles a Educação. Assistimos à retomada desarmoniosa das aulas em um formato pouco utilizado no País, o qual revelou um cenário desfavorável em vários 
sentidos. Professores e estudantes sentiram o desafio frente ao novo contexto. Diferentes condições de acesso a equipamentos, internet, habilidades para o uso de recursos de TIC, condições estruturais de moradia, tanto de professores quanto de estudantes, aumentaram a condição de desigualdade que já era grande em relação aos alunos do PAEE.

O cenário atual apresenta-se como mais um elemento desafiador aos obstáculos tradicionais do trabalho do professor da Educação Especial na oferta do AEE (PASIAN; MENDES; CIA, 2017). A atuação desse profissional, muitas vezes, demanda contato direto e próximo do aluno do PAEE para garantir os suportes necessários no contexto do ensino comum, além de acompanhamento e avaliação contínua. Vale destacar ainda, as tensões pré-existentes relacionadas à articulação do trabalho do professor da Educação Especial junto ao professor do ensino comum. Articulação fundamental para o encaminhamento das atividades do AEE, que mesmo em condições ideais, enfrenta dificuldades em viabilizar essa aproximação. $O$ contexto atual pode reforçar os desafios já existentes e comprometer a atuação do professor de Educação Especial.

Os resultados indicam que os professores perceberam que a dedicação com as aulas remotas aumentou, ao passo que a participação dos estudantes nas atividades foi reduzida. Esse fato indica que o retorno dos alunos não tem correspondido à expectativa e dedicação dos professores.

É inquestionável que as experiências vivenciadas durante as atividades remotas deixarão resquícios e muitas estratégias e recursos permanecerão, mesmo pós-covid, e farão parte do contexto escolar. Nesse ponto, é preciso criticidade na adoção das ferramentas e plataformas "deixadas" pelo ensino remoto. Embora possam ser aliadas no processo de ensino e aprendizagem, é necessário cautela no sentido das implicações de seu uso e na garantia de equidade, principalmente, para os estudantes historicamente discriminados na escola.

Recebido em: 15/10/2020 e Aprovado em: 05/11/2020

\section{Notas}

1 Alunos com deficiência, transtornos globais do desenvolvimento (incluindo Transtorno do Espectro Autista) e com altas habilidades/superdotação.

\section{Referências}

ARRUDA, Eudicio Pimenta. Educação, educação a distância e tecnologias digitais: perspectivas para a educação pós-Covid-19. Pensar a Educação em Revista, Belo Horizonte, v. 6, n. 1, mar./mai. de 2020. 
BRASIL. Decreto $n^{0}$ 7.611, de 17 de novembro de 2011. Dispõe sobre a educação especial, o atendimento educacional especializado e dá outras providências. Presidência da República. Casa Civil. Subchefia para Assuntos Jurídicos. Brasília, DF, 2011.

BRASIL. Decreto nº 9.204, de 23 de novembro de 2017. Institui o Programa de Inovação Educação Conectada. Diário Oficial da União, Brasília, DF, 2017a.

BRASIL. Decreto $n^{0} 9.057$, de 25 de maio de 2017. Regulamenta o art. 80 da Lei no 9.394, de 20 de dezembro de 1996, que estabelece as diretrizes e bases da educação nacional. Presidência da República. Secretaria Geral. Subchefia para Assuntos Jurídicos. Brasília, DF, 2017b.

BRASIL. Lei $n^{0} 14.040$ de 18 de agosto de 2020. Estabelece normas educacionais excepcionais a serem adotadas durante o estado de calamidade pública reconhecido pelo Decreto Legislativo $n^{\circ}$ 6, de 20 de março de 2020; e altera a Lei no 11.947, de 16 de junho de 2009, 2020a.

BRASIL. Parecer CNE/CP n $n^{0} 11$ de 7 de julho de 2020. Orientações Educacionais para a Realização de Aulas e Atividades Pedagógicas Presenciais e Não Presenciais no contexto da Pandemia. Conselho Nacional de Educação. Conselho Pleno: Distrito Federal/DF, 2020c.

BRASIL. Parecer CNE/CP ño 5 de 28 de abril de 2020. Reorganização do Calendário Escolar e da possibilidade de cômputo de atividades não presenciais para fins de cumprimento da carga horária mínima anual, em razão da Pandemia da COVID-19. Conselho Pleno. Conselho Nacional de Educação.: Distrito Federal/DF, 2020b.

BRASIL. Política de educação especial na perspectiva da educação inclusiva. Brasília: Ministério da Educação, 2008.

GESTRADO-CNTE. Grupo de Estudos sobre Política Educacional e Trabalho Docente - Confederação Nacional dos Trabalhadores em Educação. Trabalho docente em tempos de Pandemia: Relatório Técnico. Belo Horizonte, 2020.

GIROTO, Cláudia Regina Mosca; POKER, Rosimar Bortolini; OMOTE, Sadao. Educação Especial, formação de professores e o uso das tecnologias de informação e comunicação: a construção de práticas pedagógicas inclusivas. In: GIROTO, Cláudia Regina Mosca; POKER, Rosimar Bortolini; OMOTE, Sadao (Org.). As Tecnologias nas práticas pedagógicas inclusivas. Marília: Oficina Universitária; São Paulo: Cultura Acadêmica, p.11-24, 2012.

IANNIZZOTTO, Giancarlo; NUCITA, Andrea; FABIO, Rosa Angela; CAPRÌ, Tindara; LO BELLO, Lucia. Remote Eye-Tracking for Cognitive Telerehabilitation and Interactive School Tasks in Times of COVID-19. Information, Catania, v. 11, n. 6, jun. de 2020.

IBGE. Diretoria de Pesquisas, Coordenação de Trabalho e Rendimento. Pesquisa Nacional por Amostra de Domicílios Contínua 2017-2018, 2020.

INEP. Instituto Nacional de estudos e pesquisa educacionais Anísio Teixeira. Sinopse Estatística da Educação Básica 2019. Brasília: Inep. 2020.

LAPRAIRIE, Kimberly; HINSON, Janice. When Disaster Strikes, Move Your School Online. Journal of Educational Technology Systems, v. 35, n. 209, 209-214, 2006.

LUCAS, Megan, NELSON, Julie; SIMS. David. Schools' responses to Covid-19: Pupil engagement in remote learning. Slough: NFER. 2020.

MENDES, Enicéia Gonçalves; VILARONGA, Carla Ariela; ZERBATO, Ana Paula. Ensino colaborativo como apoio à inclusão escolar: unindo esforços entre educação comum e especial. São Carlos, SP: UFSCar, 2014. 
MOHAN, Gretta et al. Learning for all? Second-level education in Ireland during covid-19. Esri survey and statistical report series, n. 92, jun. de 2020.

OCDE. Making the Most of Technology for Learning and Training in Latin America. OECD Skills Studies, OECD Publishing: Paris, 2020.

PASIAN, Mara Silvia; MENDES, Enicéia Gonçalves; CIA, Fabiana. Aspectos da organização e funcionamento do atendimento educacional especializado: um estudo em larga escala. Educação em Revista, Belo Horizonte, v. 33, n. 33, 1-18, 2017.

REIMERS, Fernando; SCHLEICHER, Andreas. A Framework to Guide an Education Response to the COVID-19 Pandemic of 2020. OCDE: 2020.

SAMAILA, Dominic et al. Impact of Covid-19 Pandemic on People with Disabilities and its Implications on Special Education Practice in Nigeria. International Journal of Innovative Science and Research Technology, India, v. 5, n. 6, 803-808, jun. de 2020.

UNESCO. Resumo do Relatório de Monitoramento Global da Educação 2020: Inclusão e educação - Todos, sem exceção. Paris: UNESCO, 2020.

UNITED NATIONS. Policy Brief: A disability inclusive response to Covid-19. ONU: New York, 2020. 